\title{
A influência do luto no comportamento alimentar e suas implicações nas condutas nutricionais
}

\author{
The influence of mourning on feeding habits \\ and its implications for nutritional behavior
}

Maria Teresa Fialho de Sousa Campos ${ }^{1}$

${ }^{1}$ Departamento de Nutrição e Saúde, Centro de Ciências Biológicas e da Saúde, Universidade Federal de Viçosa. Av. P H Rolfs s/n, Campus Universitário. 36.571-000 Viçosa MG. mtcampos@ufv.br

\begin{abstract}
The lack of preparation for dealing with death and the absence of the loved one may lead to organic and psychological reactions that, due to the adaptive capacity of the individual to the period of mourning, may result in interference in feeding habits and consequently on the person's nutritional status. This article addresses the effects of recent mourning on feeding behavior, followed by the analysis of the dietary interview from various standpoints. This includes the postmortem nutrition and feeding habits of the bereaved and the implications of this process on hunger, on thirst and on family cooking, with a focus on nutritional behavior and on the decisions that surround it. This is a review of the literature on the theme of death and mourning, which seeks to contextualize this theme around reflections based on this experience. It emphasizes the interaction of nutrition with the science of thanatology, which is an area still not properly examined and lacking study. The identification of this influence and its implications enables better planning of food strategies, contributing greatly to actions for coping and support during mourning.
\end{abstract}

Key words Death, Mourning, Traumatic event, Stress, Feeding habits, Nutritional behavior
Resumo O despreparo para lidar com a morte e com a ausência do ente querido pode implicar em reações orgânicas e psicológicas que, em decorrência da capacidade adaptativa do indivíduo ao período de luto, acaba por interferir na condição de alimentação e, consequentemente, no estado nutricional. Este artigo aborda os efeitos do luto recente no comportamento alimentar, seguindose da análise de alguns pontos de vista da entrevista dietética; da condição de nutrição e de alimentação pós-morte do ente querido; e das implicações desse processo na fome, na sede e na culinária familiar, com enfoque nas condutas nutricionais e nas decisões que os norteiam. Trata-se de um estudo de revisão de literatura na temática morte e luto, o qual objetiva contextualizar o tema em reflexões pautadas nessa vivência, enfatizando a interação da nutrição com a ciência da tanatologia, área ainda pouco explorada e carente de estudos. A identificação dessa influência e de suas implicações permite melhor planejamento das estratégias alimentares, contribuindo sobremaneira para ações de enfrentamento e de apoio ao luto. Palavras-chave Morte, Luto, Evento traumático, Estresse, Comportamento alimentar e Conduta nutricional 


\section{Introdução}

O luto é entendido como uma importante transição psicossocial, com impacto em todas as áreas de influência humana ${ }^{1}$, razão pela qual seus efeitos no corpo e suas consequências na vida do enlutado requerem cuidados e monitoramentos efetivos. Estudar e entender a presença da morte na vida é estudar a separação amorosa ${ }^{2}$. Concebe-se, dessa forma, que o luto é a expressão dos vínculos estabelecidos entre as pessoas ${ }^{3}$; é um ritual de expressão de sentimentos profundos e íntimos ${ }^{4}$; além de ser um momento necessário para processar a perda e a dor ${ }^{5}$.

A consciência da transitoriedade humana arremete, necessariamente, à consciência da morte - a finitude, assim como a presença iminente da própria morte remete à transcendência e à necessidade da compreensão da finalidade existencial humana $^{6}$. A finitude, assim, constitui-se daquele aspecto que dá o tom necessário para tornar a vida não "algo", mas da oportunidade para "algo", cabendo ao homem encontrar sentido em cada situação, sob quaisquer condições, até mesmo nas mais lastimáveis?

Essa aproximação restrita com a morte e com tudo que ela representa e envolve alerta os profissionais para a ciência da tanatologia e suas interfaces, motivando-os na consolidação de ações pautadas nessa área, considerando sua formação básica. A tanatologia é a ciência que estuda a morte e as relações do homem com esta e suas consequências $^{8}$, buscando aprofundar os conhecimentos e as aplicações nessa área, viabilizando discussões acerca de tratamentos mais adequados, humanizados e dignos para quem sofre com a ausência do ente querido ou com a proximidade de sua própria morte ou da de outras pessoas ${ }^{9}$. Trata-se da ciência que analisa as dimensões econômicas e os aspectos biológicos, sociais, psicológicos, emocionais, legais, éticos e espirituais relativos à morte, incluindo, ainda, o pensamento em torno da morte, do morrer e do que sucede depois dela ${ }^{10}$. Dada a complexidade que envolve essa questão e dadas as múltiplas facetas em torno dela e os diversos campos de análise que se inter-relacionam com essa área da saúde, têm-se inúmeros desafios ${ }^{11}$. Questões como saber lidar com vida e morte; aprender a morrer; enfrentar a morte e a ausência física; elaborar o luto para reorganizar a vida; dentre tantas outras que norteiam o assunto, podem ter função importante para a relação entre o enlutado e o profissional, visto que o elemento emocional - a perda do ente querido ou a proximidade com a morte - estará presente no atendimento.
O Brasil tem buscado aprimorar-se nessa área, visto que, em várias capitais, há Organizações não governamentais de apoio e de enfrentamento ao luto, como também serviços especializados em tanatologia, os quais dão ênfase à equipe multiprofissional. Busca-se, com esse atendimento, aprimorar ações que possam aliviar, em parte, os sofrimentos causados pela morte, preservando a vida dos que ficam e, sobretudo, possibilitando aos trabalhadores afastados por licença médica a reabilitação funcional ou a readaptação a uma nova função - direito garantido por Leis Federais números 8112/90 e $8527 / 97^{12}$. Considerando, ain$\mathrm{da}$, que perdas significativas adoecem as pessoas e que afetam diretamente o processo de ensino e aprendizagem, a educação para a morte deveria ser contemplada na escola e na família ${ }^{6,13-15}$.

A morte desencadeia uma série de reações no campo da emoção e da razão, desarticula a mente, como aflora sentimentos diversos e tão complexos que apontam a necessidade de maiores investimentos técnico-científicos. A dor e o sofrimento que estão atrelados ao acontecimento e à vivência com a perda do ente querido são dolorosos, inevitáveis e necessários ${ }^{16}$. Mudanças no humor e no padrão comportamental, dificuldade para concentrar-se, comportamento agressivo diante dos outros e de si mesmo, fadiga, perda na regulação do sono, da fome e de autocuidados, além de múltiplos problemas somáticos, em consonância com vários sentimentos, intensificamse e associam-se à condição de resposta ao evento ou acontecimento estressor ${ }^{17}$, incluindo, na etiologia do luto, a melancolia, a sensação de impotência perante a morte e a falta de prazer com as atividades. A persistência desses sintomas e do estresse afetam ainda a função imunológica ${ }^{18}, o$ que predispõe o organismo a outros agravos à saúde, como o surgimento de enfermidades ${ }^{19}$.

A adaptação à situação vivenciada é entendida como processo dinâmico, mediante o qual os pensamentos, os sentimentos, a conduta e os mecanismos biofisiológicos mudam continuamente para ajustar-se a um ambiente em constante transformação; a ruptura do bem-estar é consequência das dificuldades em superar a vivência de experiências estressantes que desgastam o organismo na resposta orgânica e na esfera psicológica $^{20}$. O estresse é um processo complexo e multidimensional ${ }^{21}$, resultante de uma série de fenômenos que se manifestam por sinais multiformes ${ }^{19}$. Pode ser definido como desgaste geral do organismo, tanto físico como emocional, causado por alterações psicofisiológicas que ocorrem mediante esforço desencadeado por um estí- 
mulo percebido como ameaçador à homeosta$\mathrm{se}^{22}$. Os estressores, dependendo do grau de sua nocividade e do tempo necessário para o processo de adaptação, têm várias classificações. A morte súbita de pessoas insere-se na categoria de acontecimentos biográficos críticos, por serem localizáveis no tempo e no espaço, por exigirem uma reestruturação profunda da situação de vida e por provocarem reações afetivo-emocionais de longa duração ${ }^{22}$. Outros autores consideram a morte um estressor do tipo de eventos maiores ${ }^{20}$. A maioria dos indivíduos consegue lidar com o estresse comum, mas sua capacidade adaptativa é insuficiente diante de um evento inesperado e catastrófico; alguns eventos estressores podem ser desencadeados por situações da vida cotidiana e produzir efeitos comparáveis aos gerados pelas vivências em guerras ${ }^{17}$. Se a reação do organismo for muito intensa, na condição que ultrapasse a capacidade adaptativa do indivíduo, o acontecimento é classificado como estressor traumático ${ }^{22}$; a ruptura do bem-estar constituiria o distress ou forma danosa do estresse ${ }^{20}$. Quando se confronta com a morte e enfrenta o luto, o corpo reage, e as primeiras consequências mentais, emocionais e físicas aparecem. A morte do ente querido pode ser atrelada à ruptura do bem-estar, condição que afeta a rotina no trabalho, a vida social e familiar, suscitando, por parte dos profissionais, uma avaliação criteriosa e ampla, e não apenas focada no quadro clínico, ou seja, em queixas e sintomas. Investigações mais minuciosas são necessárias, para que os efeitos desse processo sejam elencados, com ética e rigor, para compor tratamentos mais individualizados, que dê ao outro (ao enlutado) a oportunidade concreta de apoio e de enfrentamento.

A ciência da nutrição insere-se nessa conjuntura, visto que o luto, geralmente, tem implicações no metabolismo e no comportamento alimentar. É difícil separar a alimentação da afetividade, pois tudo aquilo que se vive e que se sente pode interferir no comportamento alimentar ${ }^{23}$. Portanto, a maneira como se enfrenta a morte e se processa o luto tem implicações no estado nutricional. $\mathrm{O}$ objetivo deste artigo foi caracterizar o luto sob o enfoque da nutrição, com ênfase no comportamento alimentar e nas estratégias alimentares, que são respaldadas por vivências de luto.

\section{Métodos}

Realizou-se uma revisão de literatura de artigos científicos, de livros e de sites que tratassem do enfrentamento do luto e de suas repercussões na resposta orgânica e psicológica, com reflexos na alimentação. Para a elaboração do referencial teórico buscou-se, nas plataformas Bireme (BVS) e na base de dados Scielo, a expressão "morte ou luto" associada a "estresse"; "reações neuroendócrinas"; "reações psíquicas"; "hormônios do estresse"; "apetite"; "enfrentamento"; e, "velório". Outras fontes de pesquisa foram os livros e os sites específicos da Ciência da Tanatologia e de Leis, cujo enfoque está nas estratégias de enfrentamento, priorizando os referenciados pela Sociedade de Tanatologia e Cuidados Paliativos de Minas Gerais - Sotamig, pela Associação Brasileira de Apoio ao Luto e pelo Site da Sociedade Española e Internacional de Tanatologia. Livros de fisiologia aplicada à nutrição e de longevidade do cérebro também fizeram parte deste acervo, para a construção das implicações do estresse elevado na perda ou no ganho de peso corporal. Foram excluídas do referencial teórico as publicações que não mencionavam aspectos relativos ao apetite, ao consumo alimentar ou à resposta hormonal e psicológica do estresse.

\section{A associação do luto com o estado nutricional e com a entrevista dietética}

A ingestão alimentar é uma das bases do desenvolvimento das representações psíquicas ${ }^{24}$, portanto, todas as questões que possam influenciar esse processo devem ser consideradas na entrevista dietética. A compreensão de que emoções estressantes requererem discussão mais aprofundada acerca do papel do sistema nervoso central e dos fatores psicossociais na resposta ao estresse, por induzir sintomas somáticos e alterações comportamentais ${ }^{18}$, atribui relevância à morte e aos seus efeitos.

Diante do luto, torna-se fundamental retratar em que condições de nutrição se encontra $o$ enlutado, visto que o consumo inadequado, em quantidade ou em qualidade, dos alimentos pode determinar alterações no estado nutricional ${ }^{25}$. No que tange aos enlutados recentes, a perda de peso corporal significativa e rápida é uma das probabilidades em decorrência da restrição no consumo alimentar. Nas situações de agressão de natureza psicogênica, o elemento hormonal fundamental de resposta orgânica reativa é o hormônio liberador de corticotrofina $(\mathrm{CHR})^{26,27}$; por 
conseguinte, há inapetência definida e completa; redução profunda na ingestão alimentar, começando por falta de interesse pela comida; e a mastigação torna-se muito vagarosa, dentre outras reaçõe ${ }^{26}$. A recusa do alimento é outro comportamento frequente, sobretudo em casos de luto por filhos, o que compromete ainda mais o estado de saúde. O corpo emagrecido de pais enlutados traduz muito; representa o desejo da própria morte e requer intervenção imediata, por ser um padrão de comportamento caracterizado pela autoflagelação, decorrente tanto da recusa alimentar quanto do controle da fome. Por conseguinte, em condição de severa restrição alimentar, o aumento do cortisol é um fenômeno esperado, uma vez que este hormônio induz à proteólise e à lipólise para obtenção de energia ${ }^{28}$, mas a produção excessiva, devido a um estresse intenso e prolongado, torna-se prejudicial ${ }^{19}$. A privação alimentar estimula regiões do hipotálamo-, responsáveis pela ativação dos neurônios que desprendem o CHR, aumentando, dessa forma, a produção de cortisol, e a desregulação na produção e no metabolismo desse hormônio implica em mudanças nutricionais ${ }^{29}$. Ressalta-se, ainda, que a percepção de um evento traumático pelo córtex aciona um circuito cerebral subcortical, por meio das estruturas que controlam as emoções e as funções dos sistemas viscerais, e esta ativação causa, dentre várias outras reações orgânicas, a liberação de catecolaminas no hipotálamo - adrenalina e noradrenalina - que também provocam anorexia ${ }^{30,31}$, suscitando ao organismo uma resposta de enfrentamento, e os problemas aparecem quando as alterações são repetitivas por longos períodos, resultadas de uma ativação excessiva ${ }^{19}$. A morte e o luto podem alterar a sensação de fome e favorecer a perda muscular e do peso corporal devido à anorexia ou à inapetência intensa, com implicações nos mediadores hormonais, que, por sua vez, têm seus efeitos no estado nutricional.

O aumento de peso já requer outra análise, visto que pode vir a ocorrer se $\mathrm{o}$ ato de comer for atrelado à busca incessante por compensações que possam aliviar, por alguns segundos, a tristeza profunda que reluz na alma, considerando que a ansiedade gerada por esse tipo de separação possa desencadear a compulsão alimentar. $\mathrm{O}$ alimento pode ser um refúgio ${ }^{23}$, por propiciar pequenos momentos de bem-estar na dor avassaladora do luto e nas tensões psíquicas. O ganho de peso tem mecanismos que se associam também a elevadas concentrações de cortisol plasmático, que pode mediar a compulsão alimentar, uma vez que os neurônios de neuropeptídeo Y são ricos em receptores de glicocorticóides ${ }^{29}$, ou à liberação, no hipotálamo, do neuropeptídeo Y, que é o principal neuromodulador do apetite e promove a sensação de fome ${ }^{26,31}$. Frente aos níveis elevados de CHR, o organismo tenderia a excitar o fenômeno oposto, representado pela secreção do neuropeptídeo Y, numa estimulação compensatória, visando à busca do alimento ${ }^{26}$. Contudo, considerando as peculiaridades desse tipo de estresse, que se relaciona com apatia, desânimo e melancolia e que, dentre outros fatores, se associa também à falta de interesse pela vida, nem sempre a resposta compensatória esperada pela indução do neuropeptídeo Y ocorrerá, prevalecendo, no enlutado, o desinteresse pela comida; talvez esse mecanismo possibilite compreender melhor a ausência da fome pela complexidade psíquica do luto. Quando a pessoa não dispõe de estratégias de enfrentamento na situação de estresse, o eixo endócrino é disparado; dentre os seus principais efeitos está a diminuição do apetite ${ }^{32}$, condição que, somada à anedonia, pode justificar o maior número de casos de emagrecimento, nos meses subsequentes à morte do ente querido, em comparação com o ganho de peso.

No estresse, o principal hormônio liberado pela hipófise é corticotrofina ou hormônio adrenocorticotrófico (ACTH) em resposta ao CHR, que provoca o aumento na secreção de hormônios corticosteróides pelas glândulas adrenais ${ }^{30}$. Nessa condição, deve-se considerar que os níveis de corticóides e de hormônios androgênicos no organismo aumentam, principalmente se forem considerados o cortisol e a desidroepiandrosterona, respectivamente, o que indica ativação anormal do eixo hipotálamo-hipófise-suprarrenal $^{20,28,30}$. Se esta ativação for intensa e, ou, contínua, têm-se significativas correlações entre nosologias psiquiátricas e patologias clínicas e sintomas $^{33}$, razão por que o ACTH e o cortisol, dentre outros, são referenciados como hormônios do estresse ou hormônios adaptadores aos estressores $^{19}$. Níveis constantemente elevados desses hormônios acarretam uma série de reações no corpo, no cérebro e no sistema nervoso, por desequilibrar a resposta hormonal ${ }^{19,33,34}$. Esses mediadores hormonais têm efeito fisiológico distinto e mensurável nos sistemas orgânicos, sobretudo no sistema psíquico ${ }^{20,33}$, e associá-los ao comportamento alimentar permite compreender o impacto dessas alterações no estado nutricional.

Tendo em vista que a gravidade do quadro clínico nutricional está pautada na severidade da privação alimentar ou nos seus excessos, deve-se 
estar atento às razões que desencadeiam a inadequação alimentar ${ }^{35}$ durante a entrevista dietética, inserindo nesta investigação a morte e o luto. Devem-se abordar questões como: O luto está influenciando na privação ou na compulsão alimentar diagnosticada? A ausência de fome ou a diminuição severa na ingestão alimentar pode ser considerada um ato insano, frente à dor de um luto? Com qual intensidade o luto se associa ao transtorno alimentar identificado? Quais as forças de coesões determinantes nesses casos clínicos? A mudança no comportamento alimentar, que está associada ao luto, pode ser perpetuada ou agravada, caracterizando-se como parte do luto patológico? Como o enlutado percebe e avalia a perda do ente querido? A análise, em conjunto, dos exames antropométricos, clínicos, bioquímicos e imunológicos, aliada à entrevista dietética, é que permitirá ao profissional classificar o estado nutricional antes e após a experiência da morte, abrangendo, também, a condição alimentar atual do enlutado e a presença da subnutrição decorrente de carências nutricionais específicas. A associação de dois métodos dietéticos faz-se necessária, por favorecer a obtenção de mais informações, com vistas em uma análise criteriosa dos efeitos do luto na alimentação diária e na mudança comportamental. Mediante essa abordagem, tem-se subsídios para avaliar o impacto da confrontação com a morte, cujos reflexos são sentidos no contexto de vida e nos diversos comportamentos, com ênfase na mudança de hábito alimentar. O impacto que o luto causa, conforme afirmou Parkes ${ }^{1}$, necessita ser avaliado para propor medidas de intervenção. Desse modo, os sintomas identificados devem ser sempre associados ao evento traumático estressor. O tempo de luto deve ser registrado no primeiro atendimento ${ }^{36}$, por constituir um parâmetro que permite, em associação com outros dados, uma análise do desenrolar do enfrentamento. É fato que a exposição prolongada ao luto intenso interfere na capacidade adaptativa do indivíduo, uma vez que o principal fator para a desordem é ter de lidar com determinada morte e com tudo que ela representa, requerendo, nesses casos, intervenções mais contundentes para o não agravamento dos sintomas.

Em face a determinadas circunstâncias, como o é lidar com a morte de entes queridos, é normal que o indivíduo experimente sentimentos de tristeza $^{37}$ e sensações de vazio. A privação do outro traz sérias consequências, por afetar o senso de integridade do indivíduo e desestabilizar a homeostase interna ${ }^{38}$. Para quem modificou drasticamente a alimentação em decorrência do luto, antes de serem prescritas as orientações que visam restabelecer o equilíbrio nutricional, tornase fundamental o profissional compreender o processo de perdas que é inerente à morte. Tratar o luto é um processo de reparação e de elaboração de perdas, o qual vai além do ter que aprender a lidar com a ausência física da pessoa. A dor não é, portanto, a dor de perder, mas a dor da presença constante do objeto perdido e a representação de sua ausência ${ }^{39}$. Esta abordagem requer, também, a inserção de questionamentos que auxiliem na identificação do vínculo e do sentimento cultivado; do significado dessa perda e de outras que, porventura, se associem a ela; e de como o enlutado sente, percebe e identifica o processo da morte, possibilitando a expressão dos sentimentos com a vivência do luto. A condição dos sintomas do enlutado tem um significado, e a reconstrução deste tem importância essencial na elaboração da perda; assim, o processo da dinâmica do luto é individual ${ }^{40}$. Cada pessoa tende a achar maneiras ou formas para aprender a lidar com esse tipo de sofrimento. Assim, muitos acabam buscando, ao seu modo, alimentar-se, sem se preocupar com a qualidade nutricional das refeições ou com o fornecimento calórico e hídrico capaz de suprir as necessidades diárias. O ato de comer condiz com o que é de mais fácil mastigação e deglutição. A ingestão hídrica e a alimentação diária podem, nessas condições, ser modificadas em decorrência do luto, as quais, se não tratadas adequadamente, colocam o ser humano em risco de desidratação e de desnutrição.

O luto é uma experiência universal e está associado à maior morbidade e mortalidade ${ }^{41}$, motivo pelo qual requer tratamentos mais efetivos, no que concerne aos fatores terapêuticos empregados $^{42}$. Estudos demonstram que enlutados recentes buscam serviços de saúde, incluindo a emergência, e apresentam maior necessidade de atendimento clínico, maior número de internações e maior vulnerabilidade a problemas psicossomáticos ${ }^{42}$. Como parte da reação a esse tipo de perda implica na possibilidade de inadequação alimentar, dentre as mudanças fisiológicas e comportamentais elencadas à mesa, a entrevista dietética precisa considerar as particularidades do luto e as suas fases. 


\section{O velório: representações e implicações} na ausência de fome e na sensação de sede

A cerimônia fúnebre, com as singularidades que regem seus rituais, permeia múltiplos significados que alicerçam decisões que culminam com um tipo de velório/funeral. Trata-se de uma cerimônia que sofre influência das tradições e cultura do país e de suas regiões, já que contextualiza crenças e valores concebidos ${ }^{11} \mathrm{e}$ até os próprios desejos do ente querido. Independente de sepultar ou cremar, velar o corpo é importante quando se trata do viver e sentir o realismo transcendente à despedida do ente querido ${ }^{5}$. Estes desfechos finais são difíceis e penosos, visto que esse momento é marcado pela extinção do corpo $^{31}$; tem-se, aí, o confronto real com a despedida sem volta. Para Rebelo ${ }^{36}$, o confronto psicológico e o dilema mental são gerados pela assimilação racional da perda física.

O estresse que é desencadeado pelo confronto com essa despedida e com a aproximação do seu desfecho exige que se disponibilize, em local reservado e apropriado, oferta de água fresca adequada ao consumo, de água de coco, de chás feitos à base de ervas com efeito calmante (a partir de uma única erva ou pela combinação de várias), de biscoitos, dentre outras opções, como caldos e sopas. Entretanto, deve-se apreender que tanto a água como os demais produtos ofertados em cerimônias fúnebres possuem certo sabor de nostalgia, dada a privação do falecido. Bebe-se ou come-se, quase sem vontade, em pequenas quantidades, com a finalidade de atenuar o ressecamento da cavidade oral ou qualquer outra reação fisiológica que possa ser decorrente do estresse causado pela morte ${ }^{11}$. Em algumas cerimônias fúnebres, pequenos cuidados, como a oferta de líquidos e alimentos em pequenas porções, refletem o acolhimento com dignidade e demonstram que há alguém atento às necessidades dos enlutados ${ }^{5}$. Salienta-se, ainda, que essas cerimônias têm influência no sabor dos alimentos, tanto quanto na sensação de fome e de sede $^{11}$. Portanto, os sentimentos e as emoções que se associam à cerimônia fúnebre também agregam valores aos alimentos servidos, o que suscita investigação na entrevista dietética.

\section{Aprender com a morte e com o luto: reflexões sobre o acolhimento nutricional}

Aprender com a morte é um exercício diário, começando por não negá-la. Situações de morte não consentidas, de sentimentos não vivencia- dos ou não resolvidos, com relação à saudade e à tristeza, e até mesmo de extrema revolta podem fomentar um quadro clínico de luto permanente, visto que os sintomas persistem e acabam se perpetuando por anos.

Torna-se imprescindível expressar sentimentos e emoções que se associam à morte, assim como é fundamental transformar a dor que ela causa em ações proativas 5 . Ao transformar a separação em reparação, desativa-se a carga emocional negativa desse processo, que vai além da dor, permitindo o fluxo da vida ${ }^{4}$.

É importante conceber que a dor do luto não é a mesma para todos. Devem ser considerados aspectos como causa do falecimento, que nem sempre é fácil de ser verbalizada, elo familiar ou de amizade existente, idade cronológica do falecido, dentre outros. Além disso, perante evento inesperado e catastrófico, como as mortes por acidente ou por suicídio, a capacidade adaptativa dos indivíduos é insuficiente ${ }^{17}$. Concebe-se, desse modo, que não há como se inferir a dor da morte em uma escala, pois cada pessoa é única em reações intrínsecas e extrínsecas frente aos sofrimentos e às dificuldades confrontadas. Por isso, a dor da perda e sua intensidade jamais devem ser objeto de comparação. O profissional tem de saber lidar com as diferenças de cada um na elaboração do luto, enxergando além dos limites impostos por dogmas/rótulos, comumente associados à morte, transpondo barreiras na arte de comunicar-se para nutrir o ser humano além da ciência da nutrição. Embora os princípios do relacionamento interpessoal construtivo, proposto por Feldman e Miranda ${ }^{43}$, sejam fundamentais no alcance das metas estabelecidas em parceria, educar no luto é sinônimo de desafios constantes para ambos os envolvidos nessa relação - nutricionista e enlutado. Pessoas enlutadas, geralmente, trazem na sua fisionomia o reflexo da morte requerendo cautela por parte do profissional.

O luto contempla fases ${ }^{44}$ que necessitam ser aprendidas, melhor observadas, elucidadas e trabalhadas na assistência nutricional; o enlutado tem de passar por fases para alcançar um fim prático $^{45}$. Nesse processo, é essencial conversar, naturalmente, sobre o assunto, semeando reflexões e aprendizagens. Reflexões importantes acerca dos comportamentos alimentares identificados e de seus efeitos no corpo favorecem a experimentação de condutas nutricionais, incorporando as mudanças desejadas. Diferentes abordagens, estabelecendo a relação de causa e efeitos, permitem atrelar, didaticamente, as queixas e os sintomas às condutas nutricionais e aos be- 
nefícios para a saúde, despertando o interesse pela experimentação da estratégia alimentar.

Deve-se contextualizar, na condição nutricional do enlutado, a história de vida que, somada à característica de personalidade, aos padrões adaptativos de comportamento, à influência da genética familiar, à idade, à presença ou não de patologias e de cuidados relativos com a saúde, sinaliza um balanço adequado ou inadequado de energia e de nutrientes. A saúde nutricional do enlutado só pode ser promovida, recuperada ou mantida se for sustentado o adequado equilíbrio entre planejamento alimentar e metabolismo, visto que o luto leva a um processo de exaustão das energias vitais. Para que isso ocorra é fundamental adotar estratégias alimentares condizentes com as condições do luto, as quais transpõem a mudança alimentar identificada, elencando escolhas que propiciem ânimo e energia ao corpo e dêem mais sentido à vida. Desse modo, experimentar estratégias ou condutas alimentares, no princípio do tratamento, torna-se relativamente mais apropriado à adesão por parte do enlutado do que a dieta propriamente dita.

\section{O aconselhamento dietético perante o luto}

A incorporação de pequenas mudanças na alimentação, tornando os enlutados parceiros nessa decisão, é uma atitude sensata. Mediante o monitoramento quinzenal, de preferência, as condutas vão sendo mais trabalhadas e aprofundadas em conhecimentos, assim, o ajuste das porções alimentares é passível de ser concretizado com sucesso. De início, a lógica é estabelecer a mudança de comportamentos e de atitudes frente aos alimentos e aos líquidos, incluindo a ingestão de água, para, nas consultas subsequentes, ajustar a prescrição das porções mais adequadas e representativas dos grupos de alimentos, considerando a necessidade nutricional individual. O impacto das pequenas mudanças na alimentação diária, com tarefas preestabelecidas, sem um esforço demasiado por parte do enlutado, favorece a adesão ao tratamento nutricional e a satisfação com os resultados.

Com o conhecimento dos hábitos alimentares da família, a culinária deve ser resgatada, respeitando-se os limites que poderão ainda ser estabelecidos pelos enlutados. Quando, por razões diversas, o enlutado distanciar-se da culinária que desencadeia fortes lembranças, é prudente aguardar um pouco mais para se aprofundar nesse assunto. Há certos receituários que estão entrelaçados com a memória do ente querido, e tocar nessa particularidade é abrir uma cascata de emoções e de sentimentos. Tem-se, aí, outro desafio nutricional a ser trabalhado, uma vez que a memória de experiências resulta em bem-estar ou em mal-estar, quando evocada ${ }^{20}$. Resgatar receituários é sinônimo de abrir as portas para todas as suas vertentes de representações, de significados, de sensações e de lembranças diversas que a culinária possui no âmbito da família ${ }^{11}$. Para resgatar essa culinária tão singular, deve-se trabalhar, em conjunto, a representação das boas lembranças do ente querido, que, recolocadas de modo positivo, expressam também afeição e homenagem.

\section{O comportamento alimentar nos meses que sucedem a morte do ente querido: compreensão para trabalhar as estratégias alimentares}

Nos primeiros meses após o velório, a tendência do enlutado é afastar-se de tudo que dê a ele prazer. No que concerne à alimentação, os preparativos inerentes ou alusivos à culinária da casa e à ornamentação da mesa de refeições, tanto quanto o prazer com a degustação proporcionada pela comida caseira bem feita, na companhia de outras pessoas, tornam-se distantes do que parece ser o mais essencial ou vital nesse período: o de ter que aprender a lidar com o sofrimento da perda do ente querido e com todos os vazios inerentes àquela ausência. A identificação dos impactos reais e significativos no dia-a-dia do enlutado, a qual se associa diretamente à alimentação, pode favorecer escolhas mais sensatas e cabíveis das estratégias nutricionais.

$\mathrm{O}$ simples ato de posicionar-se à mesa para realizar as refeições diárias desencadeia emoções diversas e aflora fortes lembranças ${ }^{11}$. Isso requer tempo para que o enlutado possa reorganizar a mente e os seus sentimentos, em consonância com essa atitude. Diante da mesa, confronta-se com o "vazio da cadeira" que faz alusão ao vazio que há na alma de quem vivencia o luto recente. Na composição da mesa familiar, haverá um prato, um conjunto de talheres e um copo a menos, se for considerada apenas uma morte. É preciso conceder tempo aos familiares, sem que eles abandonem a estratégia de compartilhar uma das refeições diárias, que pode ser o desjejum ou uma leve ceia, até que as refeições principais tornem a ocupar o seu espaço. O ritmo de cada família, nesse retorno à mesa, é único. O importante é envolver todos os componentes da casa, possibilitando a colaboração destes com a conduta de contribuir 
para a harmonia da família na composição da mesa e impor aos enlutados menos perdas com a morte. Com o passar do tempo, a rotina em família vai ganhando vida, apesar daquela ausência. A conversa informal à mesa, dependendo do cardápio que está sendo desfrutado, pode até inserir, naturalmente, lembranças do ente querido. Assim, algumas colocações verbais retornam ao cotidiano familiar, sem tanta angústia, tais como: "se fulano estivesse aqui, não sobraria nada; esse era um dos pratos preferidos dele(a); somente ele(a) sabia preparar esse alimento como ninguém". Referenciar o ente querido à mesa de refeições passa, então, a ter significado de ótimas e inesquecíveis lembranças, que, atreladas à culinária e a tudo que ela envolve, mantêm ou preservam mais os pratos típicos da família ${ }^{11}$.

Perante o luto, alguns familiares tendem a se afastar da culinária preferida do ente querido; há, por assim dizer, repulsa por certos alimentos ou preparações que se associam a fortes recordações, já que conferem carga afetiva a esses produtos. Desse modo, se não houver uma intervenção, muitos acabam por excluir, definitivamente, as preparações alimentícias que acentuam a saudade. Entender esse processo é tornar viáveis as estratégias alimentares de reincorporação dessa culinária, que tem simbologia de "memorial". A valorização de dons intrínsecos à culinária e à arte de preparar os alimentos pode favorecer o elo entre as receitas caseiras saudáveis e a importância de preservá-las. A devida atenção a essa particularidade permite identificar os produtos e as preparações alimentícias excluídas pelo confronto com o luto ${ }^{11}$, para selecionar, de comum acordo com o enlutado, os que poderão compor a estratégia de reintegrá-los na prática alimentar. A partilha de experiências, na culinária, com outros que enfrentam o luto sedimenta também referências a novas vivências sentidas, criando oportunidades de resgatar os receituários que poderiam vir a ser perdidos no seio familiar, com o desfecho da morte. Em cada receita executada, uma história é tecida e compartilhada, concomitante com as revelações que compõem os segredos da culinária, em que cada ingrediente, além de ter sua importância na elaboração do receituário, recebe, também, a menção do ente querido, tanto nas colocações verbais quanto nos procedimentos ou detalhes que são inerentes à preparação. Pessoas enlutadas encontram suporte social de apoio bastante eficaz nos encontros ou na terapia de gru$\mathrm{po}^{4,36}$ e sentem-se encorajadas a reagir ${ }^{46}$. Essa participação permite ainda que se estabeleçam novos tipos de vínculos ${ }^{47}$. Por essa razão, a oficina de culinária, dada essa particularidade, pode ser benéfica e proveitosa para a definição de uma trajetória de luto que consubstancie a preservação de receituários de família, por permitir a expressão das emoções que entrelaçam com a história de vida dos que partiram e dos que ficaram. A degustação da culinária demonstrada tem que estar inserida no desenvolvimento da oficina, por consentir a identificação de aromas, de sabores e de texturas que se confundem com as lembranças vivas por alguém. Mesmo que os primeiros pedaços sejam amargos, pelo sentimento da perda e não pelo estímulo sensorial, os outros começam a disseminar as características sensoriais que são atribuídas à preparação e, aos poucos, já se percebem os predicados alimentares que lhes são próprios. Considerando o contexto em que a alimentação é conduzida, pode-se também optar por preparações prontas, solicitando, com antecedência, aos componentes do grupo de enlutados que preparem a receita que desejam compartilhar com os demais na composição da mesa de lanche. Ao compartilhar espaço, vivência e culinária, os pares vivenciam bons momentos, dado o caráter unificador desse processo, em razão disso, devem-se compor, também, as estratégias de enfrentamento e de apoio ao luto.

As comemorações ou celebrações festivas e seus significados têm também suas implicações à mesa. Nas celebrações habituais em família e nas datas de aniversário e de falecimento do ente querido, os sentimentos alusivos à perda intensificam-se, remexendo no equilíbrio psíquico e orgânico. Nesses períodos, o sono, o humor e o comportamento alimentar podem se alterar novamente, em resposta aos significados que essas datas representam, avivando a irreparável falta que se tem do falecido. Não há como fingir que certas datas não machucam, como não há como alterar o calendário ou pular o dia que marcou a separação dolorosa ${ }^{48}$. Aniversário de filho falecido, por exemplo, é algo extremamente singular; trata-se de uma data que desencadeia vários pensamentos; por um lado, está um rosto que se emoldurou no tempo e que nunca irá envelhecer, por outro, uma imagem de como ele(a) seria agora. Deve-se entender que, em certas ocasiões, haverá possibilidade de reações nos comportamentos, sem se tratar especificamente de um retrocesso na adaptação ao luto. Porém, sem negar as datas, a vida e as celebrações, é possível aprender a conviver com essa dor da ausência, para que ela passe a não incomodar tanto ${ }^{48}$. No começo, essa participação demanda um esforço que parecerá exacerbado, todavia, com persistência, 
tudo se acomodará para melhor. No prosseguimento de novas situações, aprende-se a articular o convívio com a presença ausente, ou com a ausência presente ${ }^{4}$. O resultado desse empreendimento de vivenciar as celebrações permite reverenciar a vida, como rememorar o ente querido, concebendo que ele(a) permanece na memória e no amor, fazendo parte de qualquer festividade. O tempo se encarregará de acomodar esses sentimentos, mas não de omiti-los plenamente, visto que o sentimento da perda não desaparece completamente. Vivenciar a vida, celebrando-a, é não perder o presente, e essa é uma das metas a serem estabelecidas com pessoas enlutadas.

Outros cuidados nutricionais, como a reposição hídrica, requerem também adaptação gradual para serem incorporados no cotidiano. A água é um componente essencial de todos os tecidos corporais ${ }^{49} \mathrm{e}$ vital para a sobrevivência humana. O estímulo, nessa reposição, deve ser dado pela busca, em pequenos volumes, de água, mais vezes ao dia, mesmo que essa atitude não esteja atrelada à sensação de sede. Deve-se começar por estabelecer uma rotina nessa busca, com intervalos definidos, mantendo essa estratégia por dois ou três dias. Assim que a rotina de reposição de líquidos for estabelecida, inicia-se o aumento gradual no volume ingerido, com o assistido devidamente instruído no procedimento desejado. Degustar pedaços de frutas com maior teor de água dá uma sensação agradável na boca, portanto, na meta de se restabelecer uma hidratação adequada, essa opção pode ser conjugada com a ingestão de água e de suco de fruta natural.

Há certos alimentos que estão associados ao estado de ânimo e de humor, e a inclusão destes no cardápio do enlutado é outra meta a ser atingida. Isso ocorre porque a liberação de substâncias que transmitem impulsos nervosos no cérebro é influenciada pela composição química dos alimentos ${ }^{11}$. Por exemplo, a produção de serotonina no organismo depende tanto da ingestão de alimentos fontes de triptofano, quanto do consumo de carboidratos, e essa combinação deve ser considerada no planejamento alimentar ${ }^{11,50}$, além da associação com outros nutrientes, como vitaminas (B6 e ácido fólico) e magnésio ${ }^{29,51}$. Essa atenção com a reposição de triptofano pode ter também efeitos na indução do sono ${ }^{52}$, visto que a serotonina, por ser precursora do hormônio melatonina, atua favoravelmente nesse processo $^{53}$. No avanço da reconstrução pessoal, o bom humor, a alegria e o amor contribuem, inegavelmente, e isto tem impulsionado pesquisas na área das ondas cerebrais responsáveis pelo estado de bem-estar e na reposição de nutrientes e de componentes alimentares que interferem na saúde mental e na produção de neurotransmissores associados a essa resposta ${ }^{11}$. Pesquisas têm comprovado, com rigor científico, o poder da mente humana na recuperação da saúde, denominando essa capacidade, inerente ao ser humano, de estado salutogênico ${ }^{54}$. Quando o enlutado é capaz de fazer projetos de vida, mesmo em circunstâncias delicadas como o é no enfrentamento do luto, a mente exerce ação na saúde ${ }^{55}$, repercutindo, favoravelmente, no estado psíquico e orgânico e beneficiando, sobremaneira, a capacidade adaptativa do indivíduo.

\section{Considerações finais}

A banalização da morte na vida das pessoas contribui, substancialmente, para o agravamento dos quadros de estresse traumático e de transtorno de adaptação. É preciso que os profissionais da área de saúde possam rever seus valores diante da morte, para que o acolhimento digno, independente de qual seja a especialidade de atuação, seja incorporado nos diversos atendimentos individuais e coletivos, no âmbito de prestação de serviço.

Nesse contexto, a inserção de conteúdos que trabalhem os conceitos teóricos e práticos da ciência da Tanatologia articulados aos princípios da nutrição humana na formação do nutricionista precisa ser concretizada, capacitando-os melhor para lidar com a transitoriedade da vida humana, a finitude e o luto.

No que concerne à associação da ciência da nutrição com a da tanatologia, há ainda carência de estudos. A sua aplicação é ampla, visto que incorpora não apenas os conceitos trabalhados neste artigo, como também os cuidados com o paciente terminal e os efeitos na culinária. Outros estudos relativos ao luto e aos seus efeitos no comportamento alimentar adicionarão informações relevantes sobre a real dimensão desse processo. A compreensão desses efeitos amplia o entendimento das condições que influenciam o consumo alimentar do enlutado, repercutindo no seu estado nutricional, e as estratégias alimentares deveriam ser incorporadas aquelas de enfrentamento e de apoio ao luto. Assim, no âmbito da saúde coletiva, poderão ser implementadas ações nutricionais específicas e mais eficazes à recuperação de pacientes traumatizados pela morte, sem negligenciar os acontecimentos que a circundam, mas com o intuito de desmistificá-la e de oferecer aos enlutados amplo acolhimento nutricional. 


\section{Referências}

1. Parkes CM. Luto: estudo sobre a perda na vida adulta - Novas buscas em psicoterapia. Tradução de Maria Helena Pereira Franco Bromberg. São Paulo: SUMMUS Editorial; 1998.

2. Caruso LA. A separação dos amantes: uma fenomenologia da morte. São Paulo: Diadorim Cortez; 1981.

3. Bromberg MHPF. Psicoterapia em situações de perda e luto. Campinas: Editora Psy; 1998.

4. Tavares GR e colaboradores. Do luto à luta. Belo Horizonte: Casa de Minas; 2001.

5. Campos MTFS. Transformando lágrimas em bênçãos. Viçosa: [s.n.]; 2009.

6. Santos RO. As religiões e educação para a morte na contemporaneidade: diálogos e interseções. In: Anais do Congresso Internacional da Faculdade EST.; 2012; São Leopoldo, EST; v. 1; p.197-207.

7. Lima Neto VB. Tanatologia e logoterapia: um diálogo ontológico. Rev. Logos \& Existência 2012; 1(1):3849.

8. D’ assumpção EA. Tanatologia: ciência da vida e da morte. Vol. 1. Belo Horizonte: Fumarc; 2002. (Coleção Biotanatologia e Bioética)

9. Kovács MJ. Morte e desenvolvimento humano. São Paulo: Casa do Psicólogo; 1992.

10. ¿Qué es la Tanatología y cuales son nuestros objetivos en tanatologia.org? [Documento da Internet]. [acessado 2011 dez. 21]. Disponível em: http:// tanatologia.org/index.html.

11. Campos MTFS, Coelho AIM. Alimentação saudável na terceira idade: estratégias úteis. $3^{a}$ Edição Atualizada e Ampliada. Viçosa: Editora UFV; 2013. (Série Soluções). No prelo 2013.

12. Brasil. Leis. Portaria MOG n.1675, de 06 de outubro de 2006. Dispõe sobre o direito a reabilitação ou readaptação do servidor público. Diário Oficial da União 2006; 10 out

13. Kovács MJ. Desenvolvimento da tanatologia: estudos sobre a morte e o morrer. Paidéia 2008; 18(41):457-468.

14. Kovácz MJ. Educadores e morte. Rev. Semestral da Associação Brasileira de Psicologia 2012; 16(1):71-81.

15. Marques PRM, Demartini ZBF. Luto na escola: um cuidado necessário. Rev. Pedagógica 2011; 14(26):4358.

16. Soares AR. Transitoriedade. Coluna Bem Viver. Jornal Estado de Minas. 2008. [online]. [acessado 2012 jun. 01] Disponível em: www.antonioroberto. com.br/2008/11/09/artigo-transitoriedade/

17. Viola TW, Schiavon BK, Renner AM, Grassi-Oliveira R. Trauma complexo e suas implicações diagnósticas. Rev. Psiquiatr. 2011; 33(1):55-62.
18. Marques AH, Solis ACO, Neto FL, Lotufo RFM, Prado EBA. Estresse, depressão, alterações imunológicas e doença periodontal. Rev. Psiq. Clín. 2001; 28(5):266-273.

19. Farné M. O estresse: às vezes é positivo, às vezes é negativo, mas pode ser transformado em um aliado. Tradução de Mário José Zambiazi. São Paulo: Paulinas, Edição Loyola; 2003.

20. Sparrenberger F, Santos I, Lima RC. Epidemiologia do distress psicológico: estudo transversal de base populacional. Rev Saude Publica 2003; 37(4):434-439.

21. McEwen BS, Seeman T. Protective and damaging effects of mediators of stress. Elaborating and testing the concepts of allostasis and allostatic load. Ann. N. Y. Acad. Sci. 1999; 896:30-47.

22. Deminco M. Jornada de trabalho e redução do estresse. Psicologado artigos. [Texto da Internet]. 2011 jun. [acessado 2012 dez. 14] Disponível em: http:// artigos.psicologado.com/atuacao/psicologiaorganizacional/jornada-de-trabalho-e-reducao-doestresse

23. Kachani AT, Kotait MS. Nutrição em psiquiatria. Nestlé Bio Nutr. Saúde 2011; 5(14):24-28.

24. Perez GH, Romano BW. Comportamento alimentar e síndrome metabólica: aspectos psicológicos. Rev. Soc. Cardiol. 2004; 14(4):544-550.

25. Engstrom EM, organizador. SISVAN: instrumento para combate aos distúrbios nutricionais em serviços de saúde. 3a Edição Atualizada e Ampliada. Rio de Janeiro: Fiocruz; 2002.

26. Douglas CR. Controle da ingestão alimentar. In: Douglas CR, organizador. Tratado de fisiologia aplicada à nutrição. São Paulo: Robe Editorial; 2002. p. 473-84.

27. Bittencourt JC. O fator-liberador de corticotrofina (CRF) e o sistema autônomo central. [Documento da Internet]. 2011 [acessado 2013 abr. 16] Disponível em: www.bv.fapesp.br $>$... $>$ pesquisa.

28. Assumpção CL, Cabral MD. Complicações clínicas da anorexia nervosa e bulimia nervosa. Rev. Bras. Psiquiatr 2002; 24(Supl. 3):29-33.

29. Naves A, Paschoal VCP. Regulação funcional da obesidade. Conscientiae Saúde 2007; 6(1):189-1999.

30. Bernik W. Estresse: o assassino silencioso. [Documento da Internet]. [acessado 2013 abr. 15] Disponível em: http://www.cerebromente.org.br/n03/ doencas/stress.htm. 
31. Gonçalves M. Comportamento alimentar e transtornos psiquiátricos. Rev. Psychiatry on line Brasil [Periódico na Internet]. 2011 mar. [acessado 2013 maio 22]; 16(3):[cerca de 8p.]. Disponível em: http:// www.polbr.med.br/ano11/prat0311.php.

32. Margis R, Picon P, Cosner AF, Silveira RO. Relação entre estressores, estresse e ansiedade. Rev. Psiquiatr. 2003; 25(Supl. 1):65-74.

33. Gonçalves M. Correlação entre alterações do eixo hipófise-hipotálamo-suprarrenal e transtornos psiquiátricos. Rev. Psychiatry on line Brasil [periódico na Internet]. 2010 abr. [acessado 2012 dez. 07]; 15(4):[cerca de 5p.] Disponível em: <http://www. polbr.med.br/ano10/prat0410.php $>$.

34. Khalsa DS. Longevidade do cérebro. Tradução de Sylvia Bello. 5a Edição. Rio de Janeiro: Objetiva; 1997.

35. Campos MTFS, Monteiro JBR, Ornelas APRC. Fatores que afetam o consumo e a nutrição do idoso. Rev. Nutr. 2000; 13(3):157-165.

36. Rebelo JE. Importância da entreajuda no apoio a pais em luto. Aná. Psicológica [periódico na Internet]. 2005 out. [acessado 2012 dez. 03]; 23(4):373380. Disponível em: www.scielo.gpeari.mctes.pt/ scielo.php?script=sci_arttext $\&$ pid $=$ S0870-82312005 000400002\&Ing=pt\&nrm=iso.

37. Instituto de Estudos e Orientação da Família (INEF). Depressão. São Paulo: Fundação Djalma Guimarães; 2003. [Documento da Internet]. [acessado 2013 maio 22] [cerca de 5p.] Disponível em: http://www.inef. com.br/depressao.htm.

38. Lima SBL. A dor da perda amorosa e a gestalt-terapia. Rev. I.G.T. [Periódico na Internet]. 2008 [acessado 2009 nov. 30]; 5(9):114-125. Disponível em: igt.psc.br/ojs2/index.php/igtnarede/article/view/ 1887/2572.

39. Caterina MC. O luto: perdas e rompimento de vínculos - APVP. Módulo 28. Associação Psicanalítica do Vale da Paraíba. [Documento da Internet].2008 [acessado 2012 nov. 30]; 42p. Disponível em: www.apvp.com.br/artigos/apostila_luto_perda.pdf.

40. Ariès P. The hour of our death. Tradução de Helen Weaver. Nova York: Editora Oxford University Press; 1981.

41. Stroebe M, Schut H, Stroebe W. Health outcomes of bereavement. Lancet 2007; 370(9603):1960-1973.

42. Silva ACO, Nardi AE. Luto pela morte de um filho: utilização de um protocolo de terapia cognitivocomportamental. Rev. Psiquiatr. 2010; 32(3):113-116.
43. Feldman C, Miranda ML. Construindo a relação de ajuda. 12a Edição. Belo Horizonte: Crescer; 2001.

44. Küblen-ross E. Sobre a morte e o morrer. 4a Edição. São Paulo: Editora Martins Fontes; 1969.

45. Volkan VD. Psicodinâmica da violência de grandes grupos e da violência de massa. Cien Saude Colet 2007; 11(Supl.):1199-1210.

46. D’assumpção EA. Grupo de suporte ao luto. São Paulo: Paulinas; 2003.

47. Cardoso C, Seminotti N. O grupo psicoterapêutico no Caps. Cien Saude Colet 2006; 11(3):775-783.

48. Campos MTFS. Os sinais: quando o amor comunica. Viçosa: [s.n.]; 2008.

49. Charney P. Água, eletrólitos e equilíbrio ácido-básico. In: Mahan LK, Escott-stump S. Krause, alimentos, nutrição e dietoterapia. Rio de Janeiro: Elsevier; 2010. p. 144-157.

50. Benton D. Carboidratos e humor. In: Benton D. Novas tendências sobre a importância dos carboidratos na nutrição. São Paulo: Danone S. A.; 2000 p. 55-61.

51. Garofolo A, Petrilli AS. Balanço entre ácidos graxos ômega-3 e 6 na resposta inflamatória em pacientes com câncer e caquexia. Rev. Nutr 2006; 19(5):611621.

52. Kapezinski F, Busnello J, Abreu MR, Carrão AD. Aspecto da fisiologia do triptofano. Rev. Psiq. Clin.1998; 25(4):158-165.

53. Andrade RV, Silva AF, Moreira FN, Santos HPS, Dantas HF, Almeida IF, Lobo LPB, Nascimento MA. Atuação dos neurotransmissores na depressão. Rev. Bras. Ciênc. Farm. [periódico na Internet]. 2003 jan./ mar. [acessado $2011 \mathrm{dez}$. 19]; 1(1):[cerca de 4p.] Disponível em: http://www.saudeemovimento.com. br/revista/artigos/cienciafarmaceuticas/v1n1a6.pdf.

54. Oliveira CC, Costa AL. Viver o estado terminal de um familiar: leitura salutogénica de resultados de um estudo de caso. Saúde Soc. 2012; 21(3):698-709.

55. Serrão D. Eutanásia, moralmente condenável, juridicamente inaceitável. Pontifícia São Paulo: Universidade Católica de São Paulo; 2005. [Texto da Internet]. 2005 abr. [acessado 2013 jan. 08]. Disponível em: www.pucsp.br

Artigo apresentado em 30/04/2013

Aprovado em 22/05/2013

Versão final apresentada em 22/05/2013 